\title{
Levels Of Learning In Mathematics Teaching And Learning
}

Enrique Ortiz, (E-mail: ortiz@mail.ucf.edu), University of Central Florida

\begin{abstract}
This paper presents the levels of teaching and learning (concrete, representational and abstract) that could be used to present ideas and concepts in different content areas at different grade levels. When used properly, the levels of learning are powerful tools, facilitators of students' development of abstract thinking (which happens in the student's mind), and effective instructional tools for meeting students' specific learning styles and interests.
\end{abstract}

\section{INTRODUCTION}

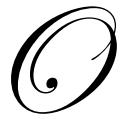

ne of the first steps for the proper and effective use of these levels of learning is the understanding their meaning. The basic levels of learning are concrete, pictorial (sometimes called pictorial or semiconcrete) and abstract (see Figure 1).

Figure 1

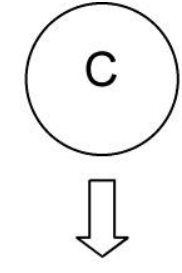

Using objects or manipulative materials.

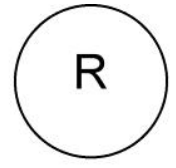

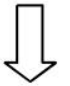

Using pictures or representation of objects or manipulative materials.

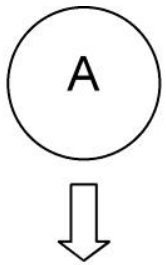

Using written words or symbols, verbal communication.

Teaching learning activities could contain these levels individually or in combination. In other words, the students might be working on an activity just using the concrete, representational or abstract level, or could be working on an activity that involves, the combination of concrete and abstract levels (see Figure 2). For the purposes of this paper, the following learning levels and combination of levels represent different phases of development:

Phase I: $\quad$ Concrete, and Concrete-to-Concrete

Phase II: $\quad$ Concrete-to-Representational or Representational-to-Concrete

Phase III: Representational, or Representational-to-Representational

Phase IV: $\quad$ Concrete-to-Abstract, or Abstract-to-Concrete

Phase V: Representational-to-Abstract, or Abstract-to-Representational

Phase VI: $\quad$ Abstract, or Abstract-to-Abstract

Phase VII: Concrete-Representational-Abstract at the same time 
Every learning activity can be represented as a point somewhere within this diagram. Though sharply defined in the diagram, the boundaries of the circles can seem unclear when classifying some learning activities. This occasional unclearness does not diminish the usefulness of this seemingly simplistic representation. The following is a description of each phase of the different learning levels. Elementary mathematics methods and content material will be used in the examples that will elaborate the phases discussed and provide some specifics.

Figure 2

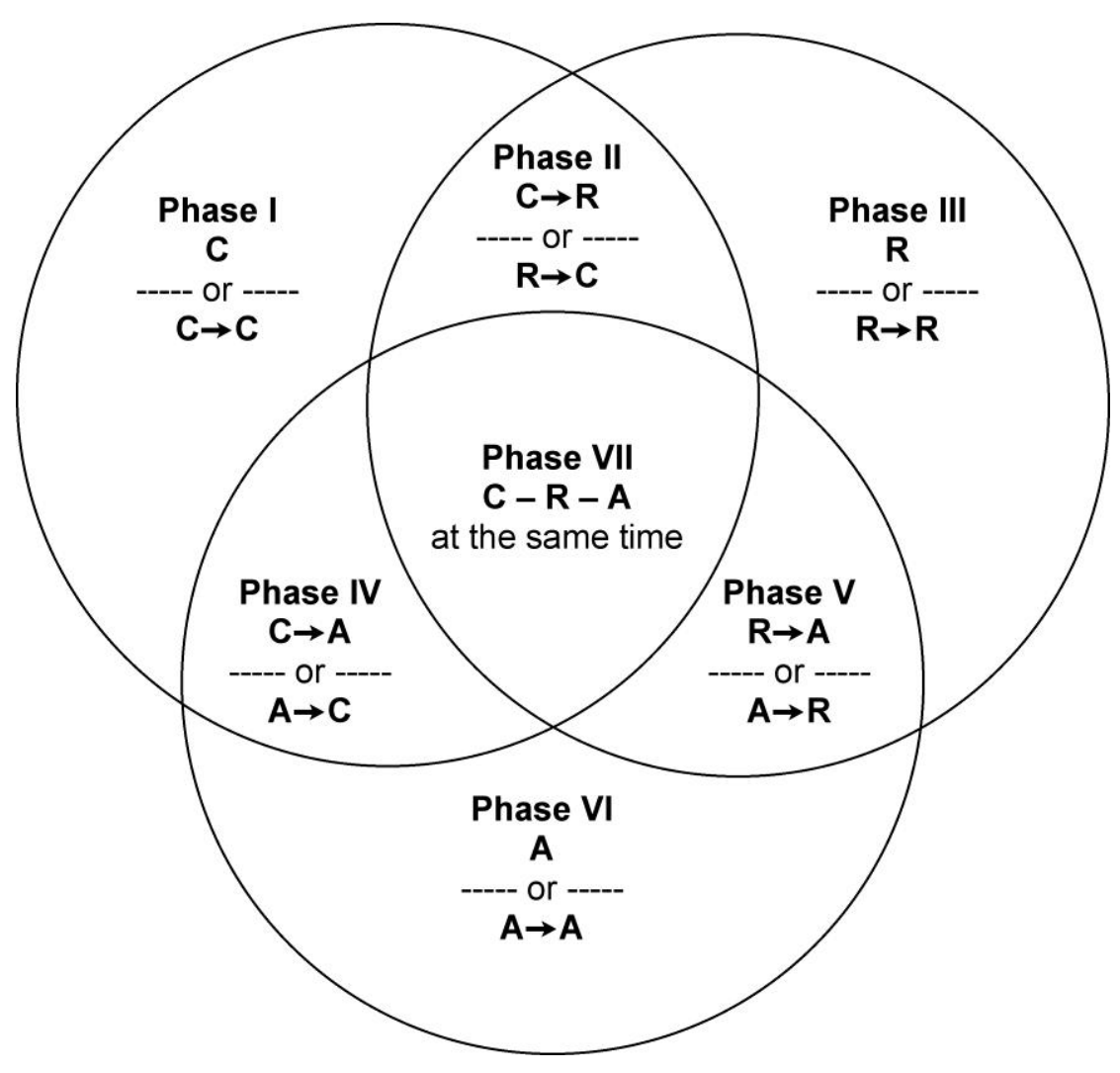

\section{PHASE I: CONCRETE LEVEL, AND CONCRETE-TO-CONCRETE COMBINATION}

The concrete level involves the use of manipulative materials or objects to model concepts or ideas, which usually happens during free play. The manipulation of the materials helps students visualize the structure and essence of the concepts or ideas. The manipulatives include but is not limited to cubes, pencils, base-ten blocks, attribute blocks, pattern blocks, people, furniture, and others. For example, a student who is playing with interlocking cubes to form (or extend) a pattern (black cube, white cube, white cube, black cube, white cube, white cube) is working at the concrete level. At this point, no verbal or written communication is needed. Any thoughts the student would have about making, or continuing the pattern (concretely) would be considered beginnings of abstract thinking.

The concrete-to-concrete combination is involved when the teacher demonstrates using pattern blocks and the student copies the pattern exactly (see Figure 3) or translates the pattern using a different color or attribute (for example shape as in Figure 4). 
Figure 3

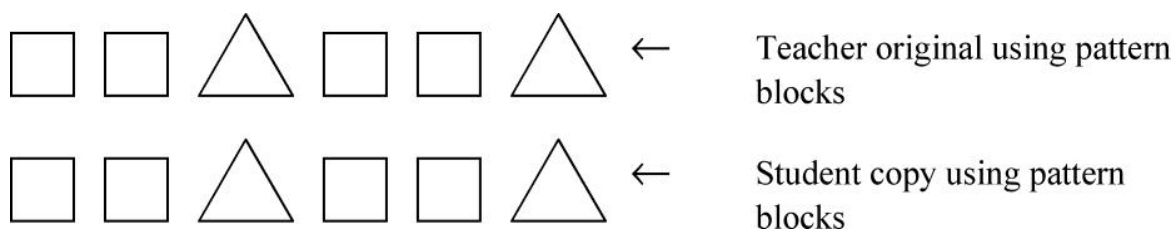

Figure 4

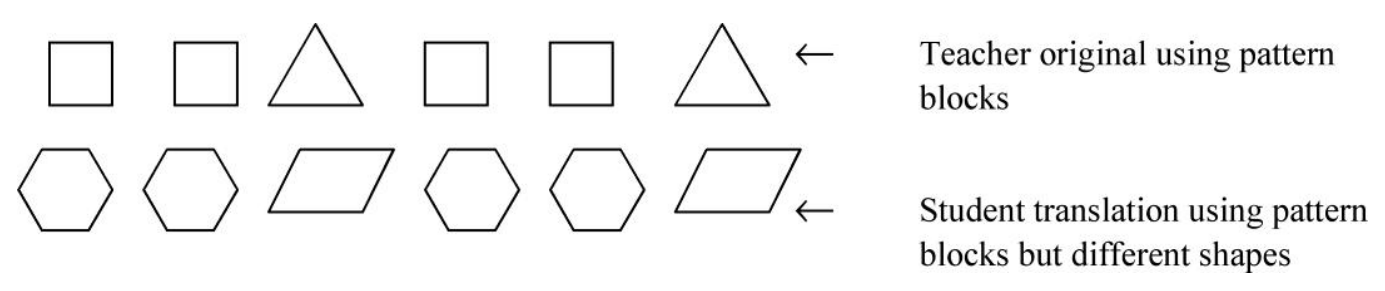

\section{PHASE II: CONCRETE-TO-REPRESENTATIONAL AND REPRESENTATIONAL-TO-CONCRETE}

The concrete-to-representational level occurs when the teacher presents the problem at the concrete level and the student translates the pattern at the representational level by drawing the shapes or coloring with crayons for example. In Figure 5, the teacher uses cubes and the student draws squares to represent the cubes, coloring the interior of squares to show the pattern. Similarly, the representational-to-concrete level combination happens when the teacher presents the pattern using a drawing and the student translates the pattern using cubes (see Figure 6).

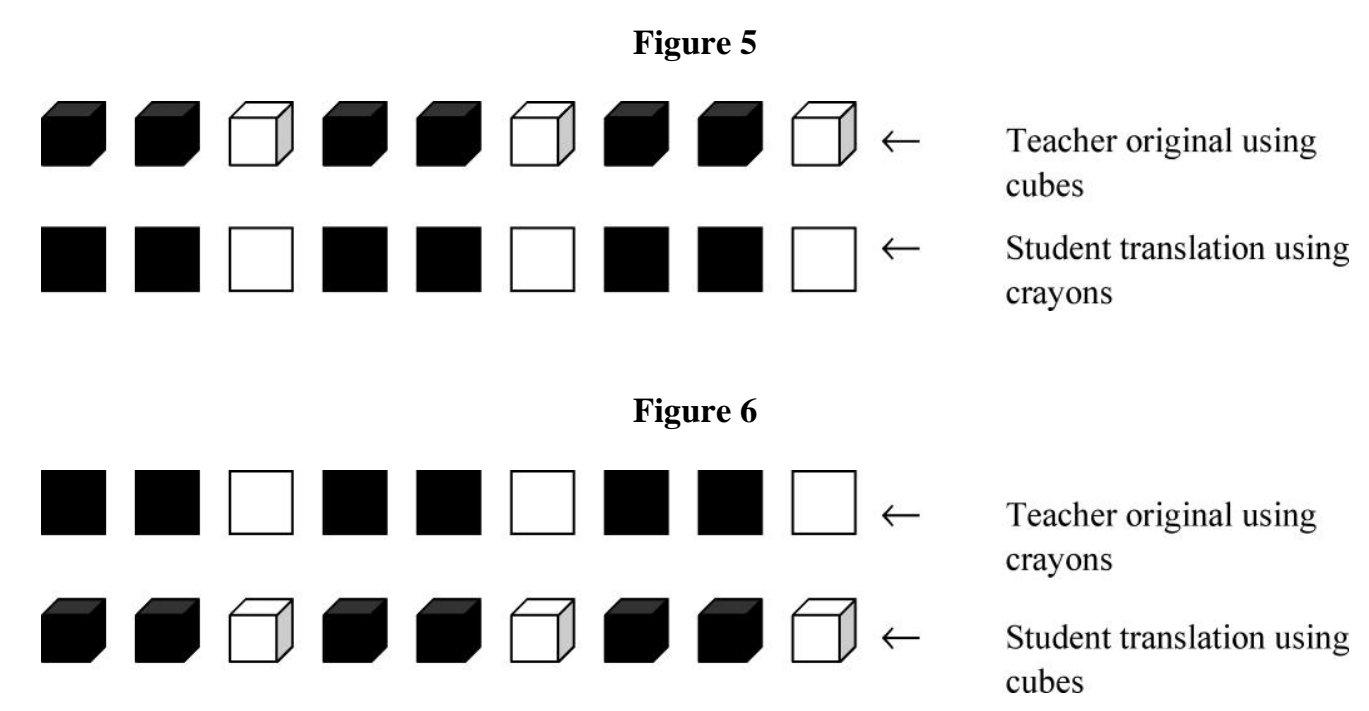

\section{PHASE III: REPRESENTATIONAL, AND REPRESENTATIONAL-TO-REPRESENTATIONAL}

The representational level involves the use of pictures or drawings of the objects or manipulative materials. This includes tally marks, overhead projections of objects on a transparency, graphical representations, and others. For the example, the student could be drawing pictures of the cubes to represent (or extend) the pattern projected 
from the overhead (see Figure 7). Again, the abstract thinking is happening in the student's mind as cubes are drawn to represent the pattern, and, at this point, no verbal or written communication is needed.

Figure 7
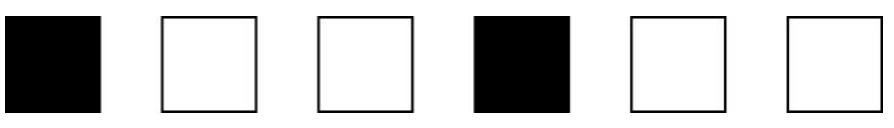

The representational-to-representational combination is involved when the teacher provides a pattern using drawings of attribute blocks and the student translates the pattern by changing the shape or size of the attribute pieces (see Figure 8).

Figure 8

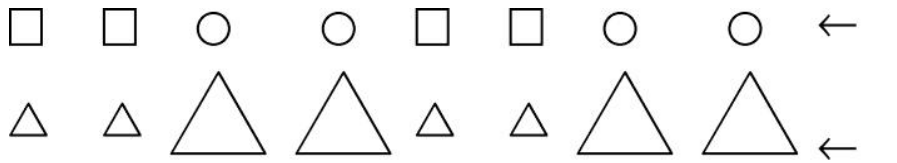

Teacher original using drawings of attribute blocks

Student copy using drawings of attribute blocks

\section{PHASE IV: CONCRETE-TO-ABSTRACT, AND ABSTRACT-TO-CONCRETE}

The concrete-to-abstract level combination is involved when the teacher presents the problem at the concrete level and the student translates the pattern at the abstract level by using words (verbally or written). For example, the teacher provides a pattern with concrete materials, and the student then translates the pattern by writing symbols (such as letters) (see Figure 9). Similarly, the abstract-to-concrete level combination is involved when the teacher presents the pattern using symbols and the student translates the pattern using colored cubes (see Figure 10).

Figure 9
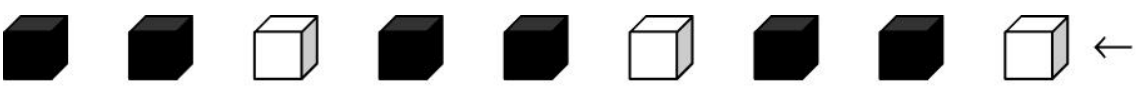

Teacher original using cubes

C $\quad \mathrm{C}$

D

C

C D

C

C

$\mathrm{D} \leftarrow$

Student translation using letters on paper

Figure 10
C $\quad$ C
D
C
C
D C
C
D $\leftarrow$
Teacher original using letters on paper
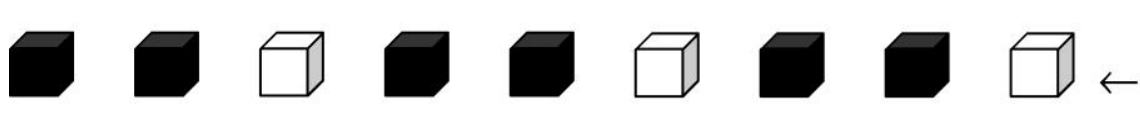
Student translation using cubes 


\section{PHASE V: REPRESENTATIONAL-TO-ABSTRACT, AND ABSTRACT-TO-REPRESENTATIONAL}

The representational-to-abstract level combination occurs when the teacher presents the problem at the representational level using drawings and the student translates the pattern to the abstract level by using words (verbally or written). For example, the teacher provides a drawn pattern, and the student then translates the pattern by writing symbols (such as numbers) (see Figure 11). Similarly, the abstract-to-representational level combination is involved when the teacher presents the pattern using symbols and the student translates the pattern using drawings (see Figure 12).

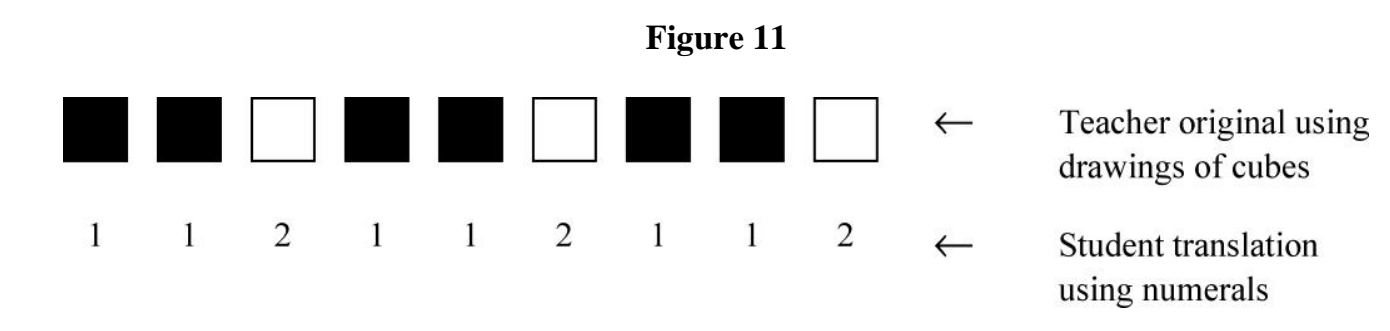

Figure 12

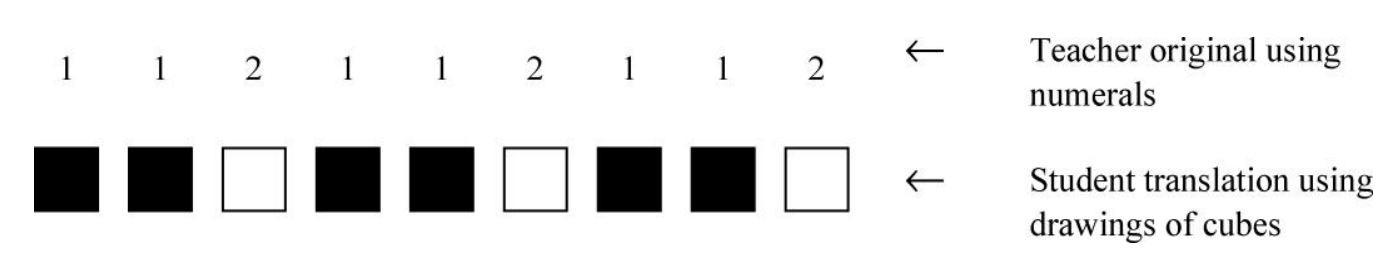

\section{PHASE VI: ABSTRACT, AND ABSTRACT-TO-ABSTRACT}

The abstract level involves the use of words, written symbols, sign language, or Braille to represent concepts or ideas. For example, the student could be using color names to represent (or extend) the pattern (using B for black and $\mathrm{W}$ for white): $\mathrm{B}, \mathrm{W}, \mathrm{W}, \mathrm{B}, \mathrm{W}, \mathrm{W}$... As before, the abstract thinking is happening in the student's mind as the color names or letters to represent the pattern are written.

The abstract-to-abstract combination is involved when the teacher provides a situation such as a pattern already made from symbols (such as letters) and the student translates the pattern by using other symbols (such as numerals) (see Figure 13).

\section{Figure 13}
A B A B A B A B $\leftarrow$ teacher original using letters
$\begin{array}{llllllllll}1 & 2 & 1 & 2 & 1 & 2 & 1 & 2 & \leftarrow & \text { student translation using numerals }\end{array}$

\section{PHASE VII: CONCRETE-REPRESENTATIONAL-ABSTRACT AT THE SAME TIME}

In a map and ruler activity, all learning levels (concrete, representational and abstract) could be present. The representational level uses the map as a scale drawing representing cities or places. The words and numerals on the map represent the abstract level. The use of the ruler for direct measurements on the map provides the concrete level. 
A Venn diagram, like in Figure 2 would be another example of a combination of the different learning levels. It can be used at the representational level to sort and classify objects (concrete level) or drawing of shapes (representational level) according to different attributes. Graphs could also provide students with different learning levels by going form one level to another without. At the concrete-to-abstract and abstract-to-concrete combinations, an activity could be done using cubes (concrete level) to graph the frequency of students' preferences for different colors (abstract level) (see Figure 14). With the representational-to-abstract and abstract-torepresentational combinations, the same activity could be adapted using a frequency table (abstract level) (see Figure 15), and/or a bar graph (representational and abstract levels see Figure 16).

\section{Figure 14}

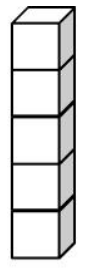

Red

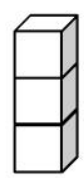

Blue

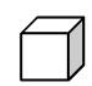

Yellow

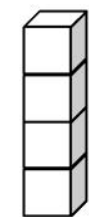

Orange

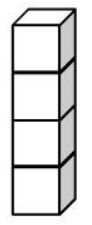

Green

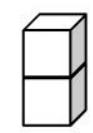

Purple

Figure 15: Frequency Table

\begin{tabular}{|c|c|}
\hline Color & Frequency \\
\hline Red & 5 \\
\hline Blue & 3 \\
\hline Yellow & 1 \\
\hline Orange & 4 \\
\hline Green & 4 \\
\hline Purple & 2 \\
\hline
\end{tabular}

Figure 16: Graph Using the Frequency Table

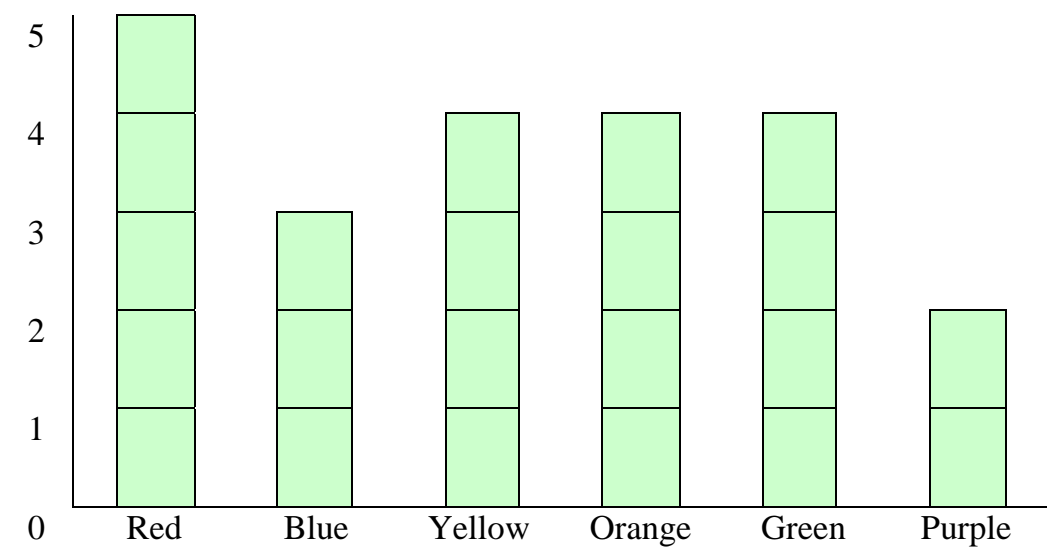




\section{CONCLUSION}

Teachers need to be able to identify the learning levels involved in different activities and match the activities to the students' learning levels. The appropriateness, effectiveness of many teaching/learning activities will depend in great part on matching learning levels to students' level of understanding of mathematical concepts. Students should be given a variety of opportunities to experience different learning levels to allow for connections and translations between levels, and transfer of knowledge. In addition, teachers should be able to assess the students' level of learning and provide experiences to enhance learning at those levels. The target is to help students move from the concrete, to the representational, to the abstract level, but also for them to be able to move from the abstract to the representational to the concrete levels with understanding and flexibility.

We need to pay attention to the different levels. Jumping from concrete to abstract and skipping the inbetween stuff defeats the purpose of using concrete at all. The teacher might as well lecture and tell the kid everything and be done with it. Without those intermediate steps, the kid does not flourish nearly as well as the kid should. No matter how smart we are, or how smart we think we are, we go from concrete through stages to abstract. As we get to abstract, generally we do not have to regress in that particular area. Yet, when we hit a new idea, we need to start at the concrete. While we might be better at learning new things, functioning in an abstract world, we do have to go through those beginning stages to learn new concepts.

Author's note: The author wishes to thank Project CENTRAL (Coordinating Existing Networks To Reach ALL Learners: http://reach.ucf.edu/ CENTRAL), which is funded by the Bureau of Instructional Support and Community Services, for their support, and, in particular, the Algebra Success Keys (ASK) team members for their valuable professional input in the development of this article. 
NOTES 